\title{
A Novel Green Synthesis of Zero Valent Iron Nanoparticles (Nzvi) using Walnut Green Skin Characterization, Catalytic Degradation and Toxicity Studies
}

\section{Asghar Hamzezadeh}

1Department of Environmental Health Engineering, School of Health, Ardabil University of Medical Sciences, Ardabil, Iran

\section{Mehdi Fazlzadeh}

1Department of Environmental Health Engineering, School of Health, Ardabil University of Medical Sciences, Ardabil, Iran

\section{Kourosh Rahmani ( $\sim$ krahmanii@yahoo.com )}

Department of Environmental Health Engineering, Mamasani Higher Education Complex for Health, Shiraz University of Medical Sciences, Shiraz, Iran

\section{Yousef poureshgh}

1Department of Environmental Health Engineering, School of Health, Ardabil University of Medical Sciences, Ardabil, Iran

\section{Research Article}

Keywords: Green synthesis, Persulfate, nZVI, Metronidazole, Toxicity test.

Posted Date: April 2nd, 2021

DOI: https://doi.org/10.21203/rs.3.rs-372024/v1

License: (c) (1) This work is licensed under a Creative Commons Attribution 4.0 International License. Read Full License 


\section{Abstract}

In the present study, green synthesized nanoparticles were used to activate persulfate and used for oxidation of metronidazole (MTZ). In the process of green synthesis, the walnut green skin was used for the synthesis of zero-valent iron (nZVI) particles. These nanoparticles' FESEM images revealed that they were spherical-shaped nanoparticles with a diameter ranging from 18 to $72 \mathrm{~nm}$. Also, the FTIR spectra indicated the functional groups of polyphenols on the surfaces of the nZVI nanoparticles. Moreover, the XRD pattern illustrated that the synthesized particles possessed a high crystalline quality structure. According to the results, under the optimum conditions, the removal efficiency of the process in degradation of MTZ was $90.3 \%$. LC-MS chromatography showed 7 by-products with reduced toxicity in the reactor outputs. It was found that the green synthesized nZVI had a good effect on the activation of the PS and the PS/nZVI process had a high ability in degradation of MTZ from aqueous solutions.

\section{Introduction}

In the last decade, the presence of pollutants in water resources has been a serious threat to the environment and pharmaceutical compounds are one of the most dangerous sources polluting the environment [1-3]. Among drug contaminants, since antibiotics are not metabolized completely during treatment and a significant proportion of them are excreted into active pharmaceutical forms that are continuously discharged, even at low concentrations; as a result they can produce bacterial resistance [4-7]. Metronidazole (MTZ) is one of the most widely used antibiotics in the world with antimicrobial and anti-inflammatory properties[8]. It is used to treat infectious diseases caused by anaerobic bacteria and protozoans such as Giardia Lamblia and Trichomonas vaginalis [9]. In addition, it is utilized as an additive in chicken and fish food to eliminate parasites $[1,5]$. Due to its low degradability and high solubility in water, this antibiotic is not removed by conventional methods and its accumulation in aquatic environments will cause side effects in humans and the environment $[10,11]$. The physical and chemical properties of MTZ can also be described in the same way (Table 1).

Several methods including adsorption, optical analysis, biodegradation [1], coagulation and centrifuge, chemical oxidation by iron salts (Ferrate), Ozonation, catalytic ozonation, photocatalytic ozonation, $\mathrm{O}_{3} / \mathrm{H}_{2} \mathrm{O}_{2}$, photo-Fenton, photocatalyst with $\mathrm{TiO}_{2}$, UV photolysis and $\mathrm{UV} / \mathrm{H}_{2} \mathrm{O}_{2}$ have been proposed to remove antibiotics from aqueous environments [12]. Today, the use of persulfate as an oxidizing agent is increasing[13]. It is a non-selective anion and a soluble, relatively stable material at room temperature and is the strongest oxidant in the peroxygen family. Its oxidation potential is $2.01 \mathrm{v}$ and compared with hydrogen peroxide $(1.8 \mathrm{v})$ and permanganate $(1.7 \mathrm{v})$. But it is slightly weaker than ozone (2.07 v) [14]. Under atmospheric conditions, persulfate oxidation does not have much effect on organic pollutants. However, if the heat, light, or certain metal ions are used as a catalyst, the reaction of persulfates increases significantly [15]. The reactions (Eqs. 1 and 2) occurring in the use of persulfates as follows [16]:

$\mathrm{S}_{2} \mathrm{O}_{8}{ }^{2-}+$ heat or UV $\rightarrow 2 \mathrm{SO}_{4}^{-\bullet}(1)$ 
$\mathrm{S}_{2} \mathrm{O}_{8}{ }^{2-}+$ Metal ions $\rightarrow \mathrm{M}^{+}+\mathrm{SO}_{4}{ }^{2-}+2 \mathrm{SO}_{4}$

Therefore, the use of metal ions, such as iron and cobalt, is one of the ways to activate persulfate. Iron has been attracting great attention because of its non-toxicity, low cost, and effectiveness. The reactions that occur with iron ion include the following reaction [17]:

$\mathrm{S}_{2} \mathrm{O}_{8}{ }^{2-}+\mathrm{Me}^{2+} \rightarrow \mathrm{SO}_{4}{ }^{--}+\mathrm{Me}^{3+}+\mathrm{SO}_{4}{ }^{2-}$

This reaction illustrates the chemical activation of PS with the intermediate metal. Among metals, the most commonly used one is $\mathrm{Fe}^{2+}$, the major disadvantages of which are high sludge production, and the consumption of $\mathrm{SO}_{4}{ }^{-} \bullet$ radicals at its high concentrations [18]. Due to problems associated with the use of this activator, nZVI from the green synthesis was used in this study, which is able to act as a permanent source of $\mathrm{Fe}^{2+}$ and reactivates it continuously. In recent years, green methods have been used to synthesize metal nanoparticles [19-22]. In these methods, the extraction of herbal products with high antioxidant capacity is used [22]. The advantage of this method is the presence of non-toxic reducing agent inside the extract[22]. As a result of the reaction of the compounds in the extract with bivalent iron, $\mathrm{nZVI}$ is synthesized $[23,24]$.

Since no studies have been conducted on the removal of MTZ by the activation of persulfate with zerovalent iron nanoparticles (synthesized by the novel "green synthesis" method), this research was selected.

\section{Materials And Methods}

\subsection{Materials and chemicals used in experiments}

MTZ was purchased from Sigma Aldrich Company. The fresh walnut green skin was obtained from the gardens of the city of Kosar, Ardabil Province, Iran. Acetonitrile (HPLC grade), ferro sulfate, sulfuric acid, sodium hydroxide, methanol and potassium persulfate were procured from German Merk Company. The instruments used included a HPLC device (CE4100, England), digital PH meter (HACH Germany), and ultrasonic (Elmasonic E 30H).

This experimental study was conducted in the Laboratory of Water and Wastewater, Faculty of Health, Ardabil University of Medical Sciences. Firstly, the nanoparticles of zero-valent iron were prepared by a green synthesis method using walnut green skin.

\subsection{Green synthesis of $\mathrm{nZVI}$ from walnut green skin}

In this research, the extract of green walnut skin was prepared by boiling $20 \mathrm{~g} / \mathrm{L}$ of walnut green skin at $60^{\circ} \mathrm{C}$ for $20 \mathrm{~min}$. After settling for 1 hour, the green skin of the walnut was filtered by a vacuum pump. Then, a $0.2 \mathrm{~N} \mathrm{FeSO}_{4}$ solution was prepared by adding $13.9 \mathrm{~g}$ of solid $\mathrm{FeSO}_{4}$ in $250 \mathrm{ml}$ distilled water. Subsequently, the $0.2 \mathrm{~N}$ solution of $\mathrm{FeSO}_{4}$ was added to the extract of the walnut green skin in a ratio of 2 to 3 . In the next step, $\mathrm{pH}$ adjustment was performed using a $1 \mathrm{~N}$ solution of sulfuric acid and sodium 
hydroxide. At this moment, the appearance of dark-colored deposits indicates the formation of the zerovalent iron nanoparticles from the extract of the walnut green skin $[25,26]$. The formed nanoparticles were separated by evaporation on a hot plate surface and collected by washing three times with deionized water and placed in nitrogen gas to prevent oxidation [25,27]. The average size and surface morphology of the nanoparticles were determined using SEM (Scanning Electron Microscope) and XRD (X-Ray Diffraction) images, respectively.

\subsection{Characterization of green synthesized nZVI}

The nano zero-valent iron particle was synthesized from the extract of green walnut skin. The highresolution transmission electron microscopy (HRTEM, CM30 Philips, Holand, 300kv), X-ray diffraction patterns of samples before and after reaction were investigated by an X-ray diffractometer (XRD, Model: X'Pert MPD, Company: Philips, Country: Holland, Tube: Co, $\lambda: 1.78897 \AA$, Step Size: $0.02^{\circ}$ /s, Operating voltage: 40 kV, Current: $40 \mathrm{~mA}$ ), FTIR (Fourier transform-infrared) spectra were obtained using an FTIR spectrometer (Perkin Elmer, Pectrum Two) in a KBr pellet. The nitrogen adsorption/desorption isotherms were studied by the BET analysis (II BELSORP mini) at $77^{\circ} \mathrm{K}$ to measure the pore volume and specific surface area of the $\mathrm{nZVI}$ and Field Emission Scanning Electron Microscope image (FESEM,MIRA3 TESCAN-XMU) analysis was used to confirm the structure of the nZVI nanoparticles.

\subsection{HPLC and LC-MS apparatuses for MTZ quantification}

The concentrations of MTZ were measured by a high performance liquid chromatography (HPLC) device (CE4100, England, CECIL equipped with the MACHERE2-NAGEL column in Germany with the specifications of $5 \mu \mathrm{M}, \mathrm{C} 18 \mathrm{ec}$, Nucleodur100-5, 250x4.6 mm with a UV-visible detector set at $230 \mathrm{~nm}$ ) with a flow rate of $1 \mathrm{ml} \cdot \mathrm{min}^{-1}$ using a mobile phase of $20 \%$ acetonitrile and $80 \%$ twice distilled water. The retention tim for MTZ was $3.17 \mathrm{~min}$. To determine the intermediates of MTZ degradation during the process, the LC-MS Machine (model: Quattro Micro API micro mass Waters 2695) of the Central Research Laboratory of Chemistry and Iran Chemical Engineering was used.

\subsection{Batch Experiments}

In this study, all the variables were optimized by means of one factor at a time OFAT. Also, all experiments were repeated three times and the average results were reported. In order to evaluate the efficiency of MTZ removal by the nano/PS process, the MTZ stoke solution was prepared according to the method described in the Standard Methods for the Examination of Water and Wastewater [28]. Then, the concentrations of $5,15,25,50$ and $75 \mathrm{mg} / \mathrm{L}$ of MTZ were obtained by stoke dilution.

Next, in a 100-ml balloon, a concentration of $25 \mathrm{mg} / \mathrm{L}$ of MTZ was prepared using the stoke solution and then transferred to a 100-ml Erlenmeyer flask and was placed on the shaker at $250 \mathrm{rpm}$ to provide the necessary mixing. In the next step, in order to prevent iron clotting in the samples, the solution $\mathrm{pH}$ was first adjusted using $0.1 \mathrm{~N}$ solutions of $\mathrm{H}_{2} \mathrm{SO}_{4}$ sulfuric acid and $\mathrm{NaOH}$. In this way, the optimum $\mathrm{pH}$ value was obtained over a 30 min of contact time. Afterwards, the optimum doses of nanoparticle and PS and contact time were obtained. Finally, under all the optimized conditions, concentrations of MTZ (1-120 
$\mathrm{mg} / \mathrm{L})$ were prepared and tested. At all steps, in order to prevent the effects of remaining nanoparticles in measuring the by-products, as well as damage to the column of the HPLC device, the samples were centrifuged at $10000 \mathrm{rpm}$ for $3 \mathrm{~min}$ before injection and then the supernatant was sampled by a 0.22 micron filtered syringe.

\subsection{Toxicity Test}

In bioassays, aquatic organisms are applied to detect or measure the impacts and potency of one or more toxic substances on living cells or tissues. In this study, the microbiological culture was used to determine the toxicity of the inlet solution and the process outlet. All used chemicals had the highest degree of purity and purchased from Merk Company (Germany). The inhibitory effect of the solution containing MTZ, treated and untreated, on a Gram-positive bacterial strain of Staphylococcus aureus ATCC 6538 and a Gram-negative Escherichia coli ATCC 25922 was evaluated.

First, in order to reach the optical density of 0.1 at a wavelength of $600 \mathrm{~nm}\left(\mathrm{OD}_{600}\right)$, each bacterial species was cultured in broth lactose culture media. The inlet (concentration: $25 \mathrm{mg} / \mathrm{L}$ ) and outlet of the reactor were sampled individually and cultured in broth lactose medium and incubated $\left(37^{\circ} \mathrm{C}\right)$. The $\mathrm{OD}_{600}$ variations of each cultured strain caused by the growth of bacterial species were measured every 2 hours for 10 hours by a spectrophotometer at a wavelength of $600 \mathrm{~nm}$. For each stage of the experiment, a control sample containing culture media and bacteria (without MTZ) was considered. Also, at each step, a sterilized solution of lactose broth was used to zero the spectrophotometer $[29,30]$.

Finally, the percentage inhibition of bacterial growth was also calculated by the following equation:

$\mathrm{GI} \%=\left[\left(1-\mathrm{OD}_{600 \mathrm{~S}} / \mathrm{OD}_{600 \mathrm{~B}}\right)\right] \times 100(6)$

GI\%: the inhibitory rate of growth

$\mathrm{OD}_{600 \mathrm{~s}}$ : optical density of the sample at a wavelength of $600 \mathrm{~nm}$

$\mathrm{OD}_{600 \mathrm{~B}}$ : optical density of control sample at a wavelength of $600 \mathrm{~nm}$

\section{Results And Discussion}

\subsection{Characterization of the $\mathrm{nZVI}$}

Figure 1 ( $a$ and $b$ ) shows the FESEM of nZVI before and after the process, illustrating the successful synthesis of the nanoparticles with an external diameter of $100 \mathrm{~nm}$. The FESEM images of $\mathrm{nZVI}$ revealed that they were both spherical shaped nanoparticles with a diameter ranging from 18 to $72 \mathrm{~nm}$. The produced nZVI particles were observed by HR-TEM (Fig. 2) and showed to have nano-sized dimensions from 20 to $50 \mathrm{~nm}$ (less than $100 \mathrm{~nm}$ ) confirming the ability of this green synthesis method to produce nZVI with a dense spherical structure and to become an economic and 'friendly environment' option than chemical production methods [20]. FTIR spectra were recorded for the nZVI before and after the oxidation 
reactions of MTZ (Fig. 3). The absorption bands at 3463,3250 and $3381 \mathrm{~cm}^{-1}$ on the nZVI surface correspond to polyphenols compounds [25]. The presence of bands attributed to polyphenolic compounds is due to $\mathrm{O}-\mathrm{H}$ stretching vibration, 3250 and $2950 \mathrm{~cm}^{-1}$ for $\mathrm{C}-\mathrm{H}$ aromatic vibration, $1623 \mathrm{~cm}^{-1}$ for $\mathrm{C}=\mathrm{C}$ band because of unsaturated hydrocarbon compounds, carbonyl group which shows heterocyclic compounds at 1104,1132 and $614 \mathrm{~cm}^{-1}$ for Fe-O stretching vibration [31]. Thus, functional groups, including polyphenols, amines and carbonyl groups of polyphenol are confirmed in the green walnut skin extracts. Meanwhile, the FTIR spectra of the prepared nZVI after the reaction displayed: stretch vibration at $604 \mathrm{~cm}^{-1}$ refer to $\mathrm{fe}^{2+}$ and $\mathrm{fe}^{3+}$ caused by the oxidation of $\mathrm{nZVI}$, as well as at 1229 and $1014 \mathrm{~cm}^{-1}$ for C-N of minor absorption of MTZ [32]. As mentioned above, the functional groups of polyphenols on the surfaces of the nZVI were confirmed.

The XRD pattern of the synthesized nZVI particles has been shown in Fig. 4. The apparent peak at the $2 \theta$ of $45^{\circ}$ indicated the presence of $\mathrm{Fe}^{0}(\mathrm{nZVI})$. The sharp and intense iron peak implies that the synthesized $\mathrm{nZVI}$ particles possess a high crystalline quality structure. Also, the XRD pattern of the prepared nanoparticles after the reaction presented the presence of $\mathrm{fe}^{3+}$ caused by the oxidation of $\mathrm{nZVI}$ at the $2 \theta$ of $33.7^{\circ}$ and $35.8^{\circ}$.

The BET surface area values of $\mathrm{nZVI}$ were studied by $\mathrm{N}_{2}$ adsorption/desorption analysis (Fig. 5. and Table 2). It is seen that the nZVI has a surface area of $149.43 \mathrm{~m}^{2} / \mathrm{g}$ with pore volume of $0.3796 \mathrm{~cm}^{3} / \mathrm{g}$. According to the literatures, the BET surface area values has been reported at levels 14.5 [33], 33.5 [34], 36.5 [35] and 3.05 [36]. In addition, the specific surface area of the commercial iron powder has been reported at 0.9 [34]. It should be noted that an increase in surface area means an increase in total amount of iron on the surfaces [37]. Therefore, the green synthesized nZVI has good properties (with $149.43 \mathrm{~m}^{2} / \mathrm{g}$ surface area) and its active participation in the oxidation reaction is approved.

Table 2

The main physical properties of $\mathrm{nZVI}$

\begin{tabular}{|llllllll|}
\hline Material & $S_{\text {BET }}$ & $S_{\text {micro }}$ & $S_{\text {meso }}$ & $V_{\text {Total }}$ & $V_{\text {micro }}$ & $V_{\text {meso }}$ & $\begin{array}{l}D_{p} \\
\end{array}$ \\
\hline $\mathrm{nZVI}$ & 149.43 & 86.56 & 62.87 & 0.3796 & 0.1123 & 0.2673 & 2.33 \\
\hline
\end{tabular}

\subsection{Effect of initial pH}

The effect of $\mathrm{pH}$ on the PS/nZVI oxidation of MTZ has been shown in Fig. 6. Because pH is the most effective parameter in the performance of chemical processes and it has a great effect on the reactions [38], in this study, the effect of $\mathrm{pH}$ changes from 3 to 11 was investigated. At pHs above $4, \mathrm{Fe}^{2+}$ ions are converted to $\mathrm{Fe}^{3+}$, which has little ability to activate PS and produce $\mathrm{SO}_{4} \bullet$. With a further increase in $\mathrm{pH}$, $\mathrm{Fe}^{3+}$ ions are converted to ferric hydroxide and increase sludge production. Also, in alkaline $\mathrm{pH}$, the 
product of PS activation is radical hydroxyl $\left(\mathrm{OH}^{\bullet}\right)$, and because in alkaline conditions, the oxidation potential of $\mathrm{OH}^{\bullet}$ is sharply reduced; as a result, the process efficiency is expected to be low even in the presence of this radical [16]. That is why the process efficiency is high in acidic conditions. Also, in neutral $\mathrm{pH}$, sulfate and hydroxyl radicals react with each other so that the reactor is free of radicals and, in turn, the process efficiency declines [39].The results of other studies also show that, in Fenton and Fenton-like processes (PS/nZVI process), the highest efficiency is reached in acidic conditions at a $\mathrm{pH}$ of 2 to $4[5,38,40]$. Particularly, acidic conditions are favorable for the formation and maintenance of ferrous ions $\left(\mathrm{Fe}^{2+}\right)$ that play an important role in producing sulfate radicals [18]. In this research, therefore, $\mathrm{pH} 3$ was selected as the optimal value.

\subsection{Effect of nano-sized zero-valent iron particles}

In order to attain maximum removal of MTZ, the optimal dose of nZVI with a constant concentration of pollutant, $\mathrm{PS}$ dosage and $\mathrm{pH}$ was determined. The findings illustrated that, in the fixed conditions and after the initial nZVI loading was raised from 0.025 to $2 \mathrm{~g} / \mathrm{L}$, degradation rate increased, respectively, from 5.8 to $94.07 \%$ (Fig. 7). By increasing the concentration of $n Z V I$ and consequently $\mathrm{Fe}^{2+}$ from the specified values, due to the occurrence of self-subsidence (Eq. 4) and the absorption of $\mathrm{SO}_{4}$ radicals by $\mathrm{Fe}^{+2}$ (Eq. 7), the efficiency of the process remains constant or decreases [39].

$\mathrm{SO}_{4}{ }^{--}+\mathrm{Fe}^{2+} \rightarrow \mathrm{SO}_{4}{ }^{2-}+\mathrm{Fe}^{3+}(7)$

Wang et al., who evaluating the efficiency of the PS/US/ZVI process in orange-acid 7 degradation, the amount of zero iron was optimized at $0.5 \mathrm{~g} / \mathrm{L}$ [41], Which is in accordance with this study.

\subsection{Effect of contact time}

To evaluate the effect of contact time on the process efficiency, first, a solution of MTZ was prepared at a concentration of $25 \mathrm{mg} / \mathrm{L}$ and its $\mathrm{pH}$ was adjusted at the optimum value. Then, in the presence of the default value of the catalyst and PS, based on previous studies, the MTZ removal efficiency was measured after the reaction at 5-150 min. As shown in Fig. 8, the removal efficacy of MTZ was $85 \%$ in 30 min. It should be pointed out that in oxidation processes the selection of a suitable contact time is of great importance, particularly in terms of designing and operating the processes. Therefore, in order to avoid increasing the reactor volume and economic conditions, the contact time of $30 \mathrm{~min}$ was regarded as the optimum amount [42]. It should be noted that this process required less reaction time. This reduction in reaction time is probably due to the production of sulfate radical resulting from the presence of $\mathrm{nZVI}$, which increases the power and speed of the removal reactions [5].

\subsection{Effect of PS dose}

At this stage of the study, the effect of different concentrations of the PS anions on the process efficiency under the optimum conditions obtained in the previous steps was investigated. To this end, nZVI and PS were added to the reactor and the process initiated. All the reactors were placed on a shaker $(250 \mathrm{rpm})$ to ensure complete mixing. Next, the samples were collected at the designated times with a 10-mL falcon 
tube, centrifuged at $10000 \mathrm{rpm}$ for $3 \mathrm{~min}$ and then filtered with a $0.22-\mu$ membrane. Finally, $1.85 \mathrm{mmol}$ dose of PS was found to be the optimal amount at $30 \mathrm{~min}$. The effect of PS dose on the MTZ degradation has been shown in Fig. 9. When PS dose was $0.1 \mathrm{mM}$, almost $6.9 \%$ of MTZ was oxidized within $30 \mathrm{~min}$. However, when the dose was further raised to $3.33 \mathrm{mM}$, approximately $4.9 \%$ of MTZ still remained in solution; it is probably due to the reaction between $\mathrm{S}_{2} \mathrm{O}_{8}{ }^{2-}$ and $\mathrm{SO}_{4}{ }^{--}$(Eq. 8) and the recombination between two $\mathrm{SO}_{4}{ }^{\bullet-}$ (Eq. 9). Thus, regarding the concentration of $\mathrm{PS}$, increasing the concentration of this substance to a specific level not only does not increase the efficiency of pollutant removal, but also become a factor for the use of sulfate radicals in the aqueous solution, which causes the process to be continuously or functionally reduce $[5,43]$. Therefore, $1.85 \mathrm{mM}$ PS was the optimal dose at $30 \mathrm{~min}$. The study by Wang et al. also confirmed the same results [41].

$\mathrm{S}_{2} \mathrm{O}_{8}{ }^{2-}+\mathrm{SO}_{4}{ }^{\bullet-} \rightarrow \mathrm{S}_{2} \mathrm{O}_{8} \bullet^{--}+\mathrm{SO}_{4}{ }^{2-}(8)$

$\mathrm{SO}_{4}^{\mathbf{0}^{-}}+\mathrm{SO}_{4}^{\mathbf{0}^{-}} \rightarrow \mathrm{S}_{2} \mathrm{O}_{8}{ }^{2-}(9)$

\subsection{Effect of initial MTZ concentration}

The effect of initial MTZ concentration on the nZVI-activated PS oxidation of MTZ has been presented in Fig. 10. Because the concentration of pollutants is an important parameter, in this section, the effect of initial concentrations of $120,100,75,50,25,10,5$ and $1 \mathrm{mg} / \mathrm{L}$ of MTZ was investigated. It is observed that, with increasing initial MTZ concentration from $1-120 \mathrm{mg} / \mathrm{L}$, the percentage removal decreased from 100 to $80.42 \%$ for the PS/nZVI process at $30 \mathrm{~min}$. Despite an increase in pollutant concentrations, the amounts of produced $\mathrm{so}_{4}{ }^{-}$are constant, resulting in a decline degradation rate [44]. As a result, the oxidation of pollutants occurs slowly at higher concentrations, which is also mentioned in the study by Wei et al. [45].

\subsection{Synergistic effects of process components}

The purpose of this section was to determine the relative effect of each of the parameters studied on the process efficiency and their synergistic effect. As shown in Fig. 11, the efficacy of MTZ removal was $14.5 \%$ when PS was utilized separately. It was also found to be $13.4 \%$ for the separate application of the zero-valent iron nanoparticles. While the process efficiency was $90.3 \%$ in the use of process components simultaneously; that is, the combined process of these two components is more efficient than their total performance separately. Therefore, the synergistic rate, in this case, was as follows: the efficacy of the PS / nZVI process was minus the separation efficiency of PS and nZVI, which was equal to $62.4 \%$ in the removal of MTZ. In the study by Liu et al., in which the synergistic degradation of acid scarlet dyeing wastewater by the ultrasound/Fenton method was tested, the efficiency rates of the separation Fenton and US processes were 40 and $4 \%$, respectively; but they reported that the combined process of Fenton/US was very effective with a removal efficiency of $90 \%$ [46]. Also, the results are similar to the previous work reported by Wang et al [41].

\subsection{By-products from MTZ degradation (LC-MS analysis)}


Chromatograms for the detection of intermediate compounds derived from MTZ oxidation during the $\mathrm{PS} / \mathrm{nZVI}$ process have been shown in Fig. 12. The chromatogram is in positive mode with TIC (total ion chromatogram) technique. The analysis time was about $10 \mathrm{~min}$ and the average sample extraction time was $2.89 \mathrm{~min}$. In comparing the peaks of Fig. 12 with the baseline peaks of the LC-MS device, there are seven known masses presented in Table 3. These seven compounds are fractions of MTZ oxidation during the process. Concerning the reduction of $70 \%$ and $53.8 \%$ of the effluent microbial toxicity of the effluent, it can be concluded that the compounds produced by the oxidation process have less toxicity and fewer risks than MTZ [47].

Table 3

Characteristics of oxidation intermediates

\begin{tabular}{|llll|}
\hline Peak number & $\mathbf{m} / \mathbf{z}$ & chemical formula & Compound name \\
\hline 1 & 58 & $\mathrm{C}_{2} \mathrm{H}_{4} \mathrm{NO}$ & Acetylamide \\
\hline 2 & 62 & $\mathrm{C}_{2} \mathrm{H}_{8} \mathrm{NO}$ & 2-Hidroxyethanaminium \\
\hline 3 & 83 & $\mathrm{C}_{4} \mathrm{H}_{7} \mathrm{~N}_{2}$ & Methylimidazolium \\
\hline 5 & 91 & $\mathrm{C}_{6} \mathrm{H}_{5} \mathrm{~N}$ & Cyclopentadienecarbonitrile \\
\hline 6 & 101 & $\mathrm{C}_{4} \mathrm{H}_{8} \mathrm{~N}_{2} \mathrm{O}$ & 2-Hydroxyethyl amino \\
\hline 7 & 103 & $\mathrm{C}_{4} \mathrm{H}_{11} \mathrm{~N}_{2} \mathrm{O}$ & 2-Acetamidoethanaminium \\
\hline
\end{tabular}

\subsection{Test for Bacterial Growth Inhibition}

The results for measuring the toxicity level using the bioassay method, the growth inhibition percentage (GI\%), have been presented in Table 4. In determining biological indicators, it is necessary that they are selected from species that are abundant in the environment and can be easily cultivated in common culture media. Therefore, as two species of Escherichia coli (gram negative) and Staphylococcus aureus (gram positive), which have these characteristics and are found in abundance in wastewater, were selected as bioassay indicators. The average 10-hour growth inhibition percentage calculated by Eq. 6 for the Escherichia coli was $26.8 \%$ of the reactor's inlet solution to $8 \%$ for the reactor's outlet solution ( $70 \%$ reduction in toxicity) and for the Staphylococcus aureus bacterium from $15.6 \%$ of the inlet solution decreased to $7.2 \%$ of the outlet solution (53.8\% reduction in toxicity). As indicated by the microbial growth patterns, the toxicity of the inlet solution after the treatment is reduced, which is consistent with the findings of Rahmani et al. in the removal of sulfathiazole $(30 \%)$ and sulfamethoxazole $(48 \%)[29,48]$. 
In bioassay study, the percentage growth inhibition (GI\%) of selected bacteria in the outlet solution of $\mathrm{PS} / \mathrm{nZVI}$ process was reduced.

Table 4

Toxicity changes in influent and effluent of the reactor

\begin{tabular}{|lllll|}
\hline & \multicolumn{2}{l}{ S. aureus growth inhibitory percent } & \multicolumn{2}{l|}{ E. coli growth inhibitory percent } \\
\hline Time (h) & Influent(\%) & Effluent(\%) & Influent(\%) & Effluent(\%) \\
\hline 2 & 19.1 & 8.9 & 38 & 13 \\
\hline 4 & 18.3 & 10.1 & 25.2 & 7.3 \\
\hline 6 & 14.8 & 8.1 & 24.3 & 5.9 \\
\hline 8 & 14.2 & 5.9 & 22.7 & 6.4 \\
\hline 10 & 13.1 & 5.6 & 25.1 & 9.9 \\
\hline Average 10 hours & 15.6 & 7.2 & 26.8 & 8 \\
\hline
\end{tabular}

\section{Conclusion}

In this study, the zero-valent iron nanoparticles synthesized by a "green synthesis" method, as a new catalyst for MTZ removal, were used by the AOP. The properties of these nanoparticles were studied using FESEM, FTIR, TEM, BET and XRD techniques. These nanoparticles had dimensions of less than $100 \mathrm{~nm}$ and had a positive effect on the PS / nZVI process by the activating PS to sulfate radicals with a $2.6 \mathrm{~V}$ oxidation potential and increasing the removal efficiency. The results showed that the PS/nZVI process had a significant effect (90.3\%) on MTZ removal under the optimal conditions: $\mathrm{pH}=3$, PS concentration $=1.85 \mathrm{mM}, \mathrm{nZVI}$ dosage $=0.5 \mathrm{gr} / \mathrm{L}$ and contact time $=30 \mathrm{~min}$. It was also found that the PS $/ \mathrm{nZVI}$ process was much better in removing MTZ compared to $\mathrm{nZVI}$ and PS alone (62.4\% increase). Also, during the process, the toxicity of the effluent had been reduced, which indicates the lower toxicity of products derived from the decomposition of MTZ based on the LC-MS results. Therefore, the PS/nZVI process can be used as an effective technology for the removal of MTZ from aqueous solutions due to high efficiency, low cost and reduced toxicity of reactor outputs.

\section{Declarations}

\section{Acknowledgment}

The present paper is the result of a master's thesis in the field of environmental health engineering approved by the Vice Chancellor for Education of Ardabil University of Medical Sciences and Health Services with a design code of 2.9507, which is hereby appreciated. 


\section{References}

1. Z. Fang, J. Chen, X. Qiu, X. Qiu, W. Cheng, L. Zhu, Effective removal of antibiotic metronidazole from water by nanoscale zero-valent iron particles. Desalination 268, 60-67 (2011)

2. Z. Heidarinejad, O. Rahmanian, M. Fazlzadeh, M. Heidari, Enhancement of methylene blue adsorption onto activated carbon prepared from Date Press Cake by low frequency ultrasound. J. Mol. Liq. 264, 591-599 (2018)

3. A.R. Rahmani, A. Shabanloo, M. Fazlzadeh, Y. Poureshgh, M. Vanaeitabar, Optimization of sonochemical decomposition of ciprofloxacin antibiotic in US/PS/nZVI process by CCD-RSM method. Desalination and Water Treatment 145, 300-308 (2019)

4. N.S. Shah, A.D. Rizwan, J.A. Khan, M. Sayed, Z.U.H. Khan, B. Murtaza, J. Iqbal, S.U. Din, M. Imran, M. Nadeem, A.a.H. Al-Muhtaseb, N. Muhammad, H.M. Khan, M. Ghauri, G. Zaman, Toxicities, kinetics and degradation pathways investigation of ciprofloxacin degradation using iron-mediated $\mathrm{H} 2 \mathrm{O} 2$ based advanced oxidation processes. Process Saf. Environ. Prot. 117, 473-482 (2018)

5. R. Khosravi, A. Zarei, M. Heidari, A. Ahmadfazeli, M. Vosughi, M. Fazlzadeh, Application of ZnO and TiO 2 nanoparticles coated onto montmorillonite in the presence of $\mathrm{H} 2 \mathrm{O} 2$ for efficient removal of cephalexin from aqueous solutions. Korean J. Chem. Eng. 35, 1000-1008 (2018)

6. R. Shokoohi, M.T. Samadi, M. Amani, Y. Poureshgh, Optimizing laccase-mediated amoxicillin removal by the use of box-behnken design in an aqueous solution. Desalination and Water Treatment 119, 53-63 (2018)

7. R. Shokoohi, M.T. Samadi, M. Amani, Y. Poureshgh, Modeling and optimization of removal of cefalexin from aquatic solutions by enzymatic oxidation using experimental design. Braz. J. Chem. Eng. 35, 943-956 (2018)

8. C.G. Sørensen, W.K. Karlsson, F.M. Amin, M. Lindelof, Metronidazole-induced encephalopathy: a systematic review. Journal of neurology 267, 1-13 (2020)

9. A.C. Nogueira, L.E. Gomes, J.A. Ferencz, J.o.E. Rodrigues, R.V. Goncalves, H. Wender, Improved visible

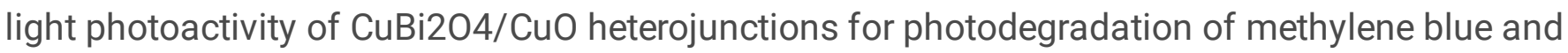
metronidazole. J. Phys. Chem. C 123, 25680-25690 (2019)

10. M. Stan, I. Lung, M.-L. Soran, C. Leostean, A. Popa, M. Stefan, M.D. Lazar, O. Opris, T.-D. Silipas, A.S. Porav, Removal of antibiotics from aqueous solutions by green synthesized magnetite nanoparticles with selected agro-waste extracts. Process Saf. Environ. Prot. 107, 357-372 (2017)

11. M. Forouzesh, A. Ebadi, A. Aghaeinejad-Meybodi, Degradation of metronidazole antibiotic in aqueous medium using activated carbon as a persulfate activator. Separation and purification technology 210, 145-151 (2019)

12. A.G. Gonçalves, J.J. Órfão, M.F.R. Pereira, Catalytic ozonation of sulphamethoxazole in the presence of carbon materials: catalytic performance and reaction pathways. J. Hazard. Mater. 239, 167-174 (2012) 
13. W.-D. Oh, Z. Dong, T.-T. Lim, Generation of sulfate radical through heterogeneous catalysis for organic contaminants removal: current development, challenges and prospects. Appl. Catal. B 194, 169-201 (2016)

14. L. Hou, H. Zhang, X. Xue, Ultrasound enhanced heterogeneous activation of peroxydisulfate by magnetite catalyst for the degradation of tetracycline in water. Sep. Purif. Technol. 84, 147-152 (2012)

15. W.H. Wang, G.E. Hoag, J.B. Collins, R. Naidu, Evaluation of surfactant-enhanced in situ chemical oxidation (S-ISCO) in contaminated soil. Water Air Soil Pollut. 224, 1713 (2013)

16. L. Zhou, W. Zheng, Y. Ji, J. Zhang, C. Zeng, Y. Zhang, Q. Wang, X. Yang, Ferrous-activated persulfate oxidation of arsenic (III) and diuron in aquatic system. J. Hazard. Mater. 263, 422-430 (2013)

17. M. Ahmad, A.L. Teel, R.J. Watts, Mechanism of persulfate activation by phenols. Environ. Sci. Technol. 47, 5864-5871 (2013)

18. S.-Y. Oh, S.-G. Kang, P.C. Chiu, Degradation of 2, 4-dinitrotoluene by persulfate activated with zerovalent iron. Sci. Total Environ. 408, 3464-3468 (2010)

19. M. Hassanpour, H. Safardoust-Hojaghan, M. Salavati-Niasari, Degradation of methylene blue and Rhodamine B as water pollutants via green synthesized Co304/ZnO nanocomposite. J. Mol. Liq. 229, 293-299 (2017)

20. I. Ali, Z.A. Alothman, M.M. Sanagi, Green Synthesis of Iron Nano-Impregnated Adsorbent for Fast Removal of Fluoride from Water. J. Mol. Liq. 211, 457-465 (2015)

21. R. Khani, B. Roostaei, G. Bagherzade, M. Moudi, Green synthesis of copper nanoparticles by fruit extract of Ziziphus spina-christi (L.) Willd.: Application for adsorption of triphenylmethane dye and antibacterial assay. J. Mol. Liq. 255, 541-549 (2018)

22. T. Pasinszki, M. Krebsz, Synthesis and Application of Zero-Valent Iron Nanoparticles in Water Treatment, Environmental Remediation, Catalysis, and Their Biological Effects. Nanomaterials 10, 917 (2020)

23. M.N. Nadagouda, A.B. Castle, R.C. Murdock, S.M. Hussain, R.S. Varma, In vitro biocompatibility of nanoscale zerovalent iron particles (NZVI) synthesized using tea polyphenols. Green Chem. 12, 114$122(2010)$

24. L. Katata-Seru, T. Moremedi, O.S. Aremu, I. Bahadur, Green synthesis of iron nanoparticles using Moringa oleifera extracts and their applications: Removal of nitrate from water and antibacterial activity against Escherichia coli. J. Mol. Liq. 256, 296-304 (2018)

25. M. Fazlzadeh, K. Rahmani, A. Zarei, H. Abdoallahzadeh, F. Nasiri, R. Khosravi, A novel green synthesis of zero valent iron nanoparticles (NZVI) using three plant extracts and their efficient application for removal of $\mathrm{Cr}(\mathrm{VI})$ from aqueous solutions. Adv. Powder Technol. 28, 122-130 (2017)

26. M. Stefaniuk, P. Oleszczuk, Y.S. Ok, Review on nano zerovalent iron (nZVI): from synthesis to environmental applications. Chem. Eng. J. 287, 618-632 (2016)

27. M. Leili, M. Fazlzadeh, A. Bhatnagar, Green synthesis of nano-zero-valent iron from Nettle and Thyme leaf extracts and their application for the removal of cephalexin antibiotic from aqueous solutions. 
Environ. Technol. 39, 1158-1172 (2018)

28. L.S. Clesceri, A.E. Greenberg, A.D. Eaton, Standard methods for the examination of water and wastewater (APHA, AWWA and WPCF, Washington DC, 1996)

29. K. Rahmani, M.A. Faramarzi, A.H. Mahvi, M. Gholami, A. Esrafili, H. Forootanfar, M. Farzadkia, Elimination and detoxification of sulfathiazole and sulfamethoxazole assisted by laccase immobilized on porous silica beads. International Biodeterioration \& Biodegradation 97, 107-114 (2015)

30. S.D. Ashrafi, S. Rezaei, H. Forootanfar, A.H. Mahvi, M.A. Faramarzi, The enzymatic decolorization and detoxification of synthetic dyes by the laccase from a soil-isolated ascomycete, Paraconiothyrium variabile. International Biodeterioration \& Biodegradation 85, 173-181 (2013)

31. S. Zha, Y. Cheng, Y. Gao, Z. Chen, M. Megharaj, R. Naidu, Nanoscale zero-valent iron as a catalyst for heterogeneous Fenton oxidation of amoxicillin. Chem. Eng. J. 255, 141-148 (2014)

32. T. Wang, J. Lin, Z. Chen, M. Megharaj, R. Naidu, Green synthesized iron nanoparticles by green tea and eucalyptus leaves extracts used for removal of nitrate in aqueous solution. J. Clean. Prod. 83, 413-419 (2014)

33. Y.-P. Sun, X. Li, J. Cao, W. Zhang, H.P. Wang, Characterization of zero-valent iron nanoparticles. Advances in colloid and interface science 120, 47-56 (2006)

34. C.-B. Wang, W.-X. Zhang, Synthesizing nanoscale iron particles for rapid and complete dechlorination of TCE and PCBs. Environ. Sci. Technol. 31, 2154-2156 (1997)

35. Y. Liu, S.A. Majetich, R.D. Tilton, D.S. Sholl, G.V. Lowry, TCE dechlorination rates, pathways, and efficiency of nanoscale iron particles with different properties. Environ. Sci. Technol. 39, 1338-1345 (2005)

36. S. Afshin, Y. Rashtbari, M. Shirmardi, M. Vosoughi, A. Hamzehzadeh, Adsorption of Basic Violet 16 dye from aqueous solution onto mucilaginous seeds of Salvia sclarea: kinetics and isotherms studies. DESALINATION AND WATER TREATMENT 161, 365-375 (2019)

37. N.T.T. Huyen, N.H. Nhung, L. Thanh, P.D. Khanh, T.D. Lam, H.A. Son, Preparation and characterization of zerovalent iron nanoparticles. Vietnam Journal of Chemistry 56, 226-230 (2018)

38. M. Gholami, K. Rahmani, A. Rahmani, H. Rahmani, A. Esrafili, Oxidative degradation of clindamycin in aqueous solution using nanoscale zero-valent iron/H2O2/US. Desalination and Water Treatment 57, 13878-13886 (2016)

39. S. Rodriguez, L. Vasquez, D. Costa, A. Romero, A. Santos, Oxidation of Orange G by persulfate activated by Fe (II), Fe (III) and zero valent iron (ZVI). Chemosphere 101, 86-92 (2014)

40. C. Özdemir, M.K. Öden, S. Şahinkaya, E. Kalipçi, Color removal from synthetic textile wastewater by sono-fenton process. Clean-Soil, Air, Water 39, 60-67 (2011)

41. X. Wang, L. Wang, J. Li, J. Qiu, C. Cai, H. Zhang, Degradation of Acid Orange 7 by persulfate activated with zero valent iron in the presence of ultrasonic irradiation. Sep. Purif. Technol. 122, 41-46 (2014) 
42. R. Shokouhi, Y. Poureshgh, H. Almasi, A. Shabanloo, Sonochemical Oxidation of Phenol using Persulfate Activated by Zerovalent Iron Nanoparticles in Aqueous Environments. J Occup Environ Health 2, 7-17 (2016)

43. S. Yang, X. Yang, X. Shao, R. Niu, L. Wang, Activated carbon catalyzed persulfate oxidation of Azo dye acid orange 7 at ambient temperature. J. Hazard. Mater. 186, 659-666 (2011)

44. G. Moussavi, M. Mahmoudi, Degradation and biodegradability improvement of the reactive red 198 azo dye using catalytic ozonation with MgO nanocrystals. Chem. Eng. J. 152, 1-7 (2009)

45. X. Wei, N. Gao, C. Li, Y. Deng, S. Zhou, L. Li, Zero-valent iron (ZVI) activation of persulfate (PS) for oxidation of bentazon in water. Chem. Eng. J. 285, 660-670 (2016)

46. T. Liu, Y.Q. Zhang, Synergistic Degradation of Acid Scarlet Dyeing Wastewater by the Ultrasound/Fenton Method. Appl. Mech. Mater. 448-453, 34-37 (2014)

47. P. Lanzky, B. Halting-Sørensen, The toxic effect of the antibiotic metronidazole on aquatic organisms. Chemosphere 35, 2553-2561 (1997)

48. L. Rizzo, Bioassays as a tool for evaluating advanced oxidation processes in water and wastewater treatment. Water Res. 45, 4311-4340 (2011)

\section{Tables}

Due to technical limitations, table 1 is only available as a download in the Supplemental Files section.

\section{Figures}

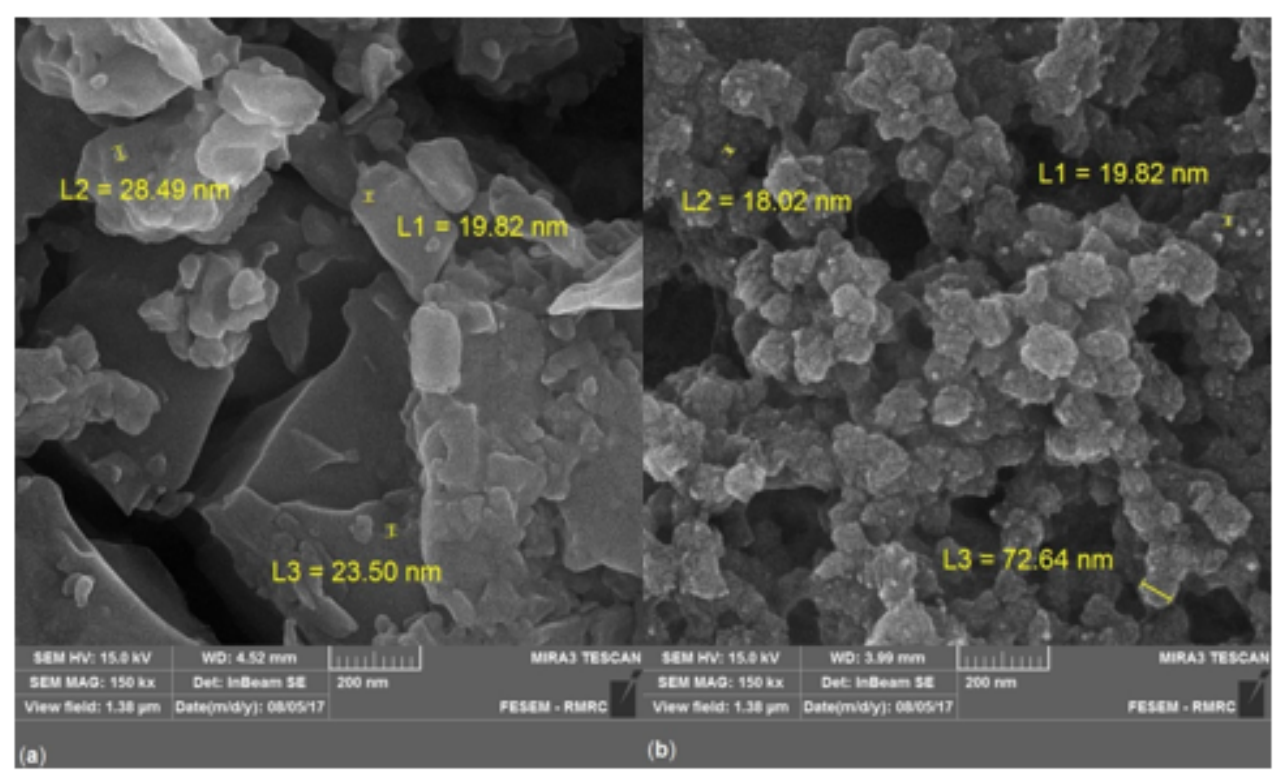

Figure 1

FESEM images of the prepared nZVI (a) Before oxidation (b) after oxidation 


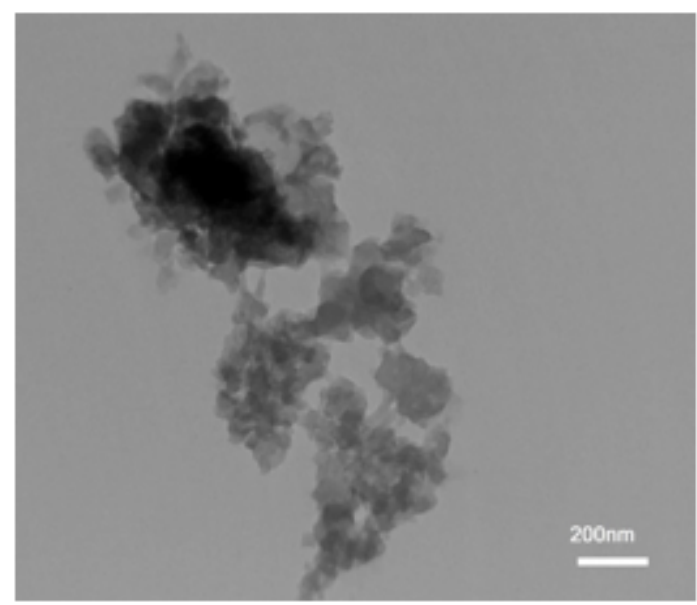

Figure 2

HR-TEM image of the prepared $\mathrm{nZVI}$
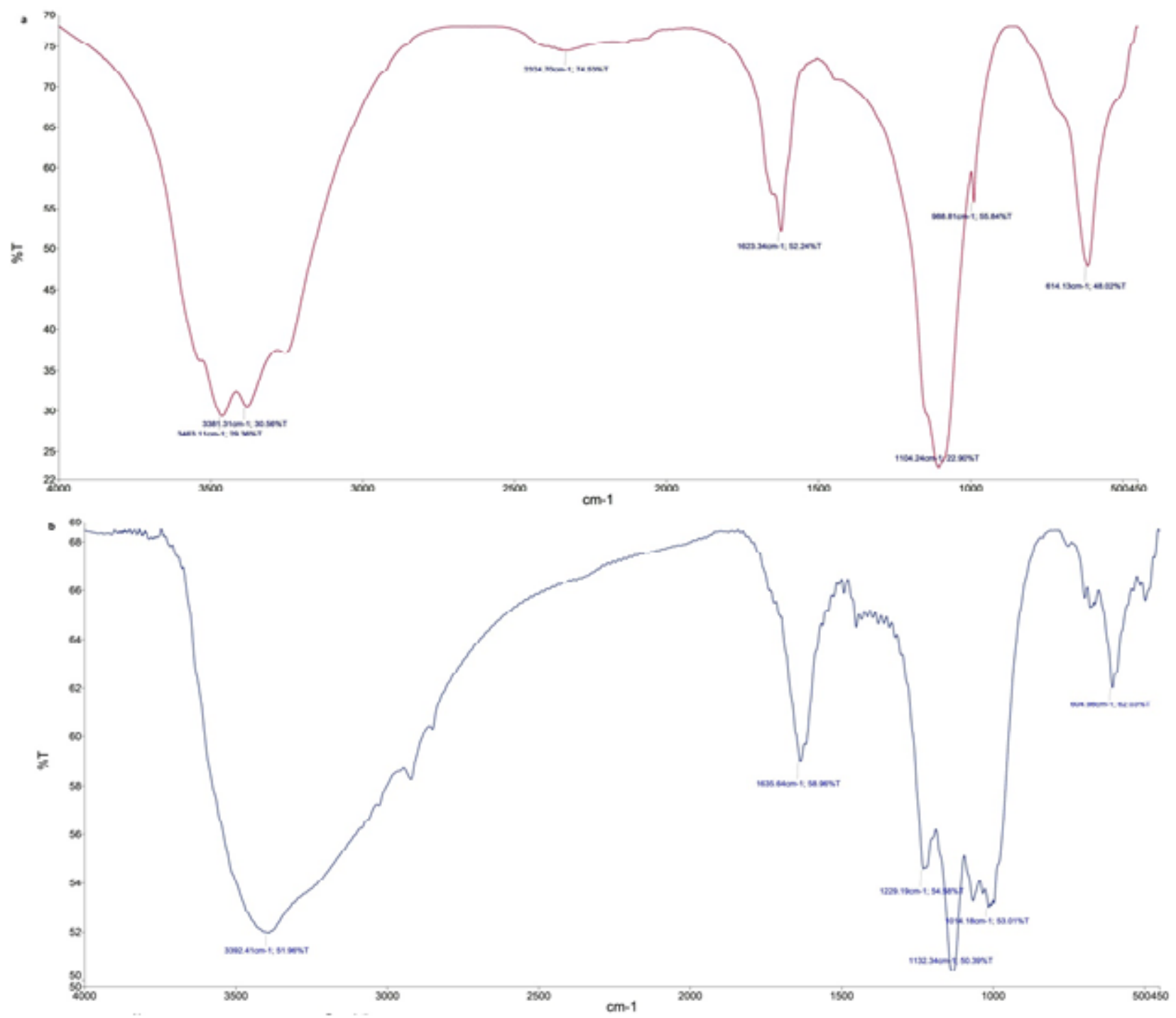

Figure 3 
FT-IR spectra of the green synthesized nanoparticles: (a) before and (b) after the reaction

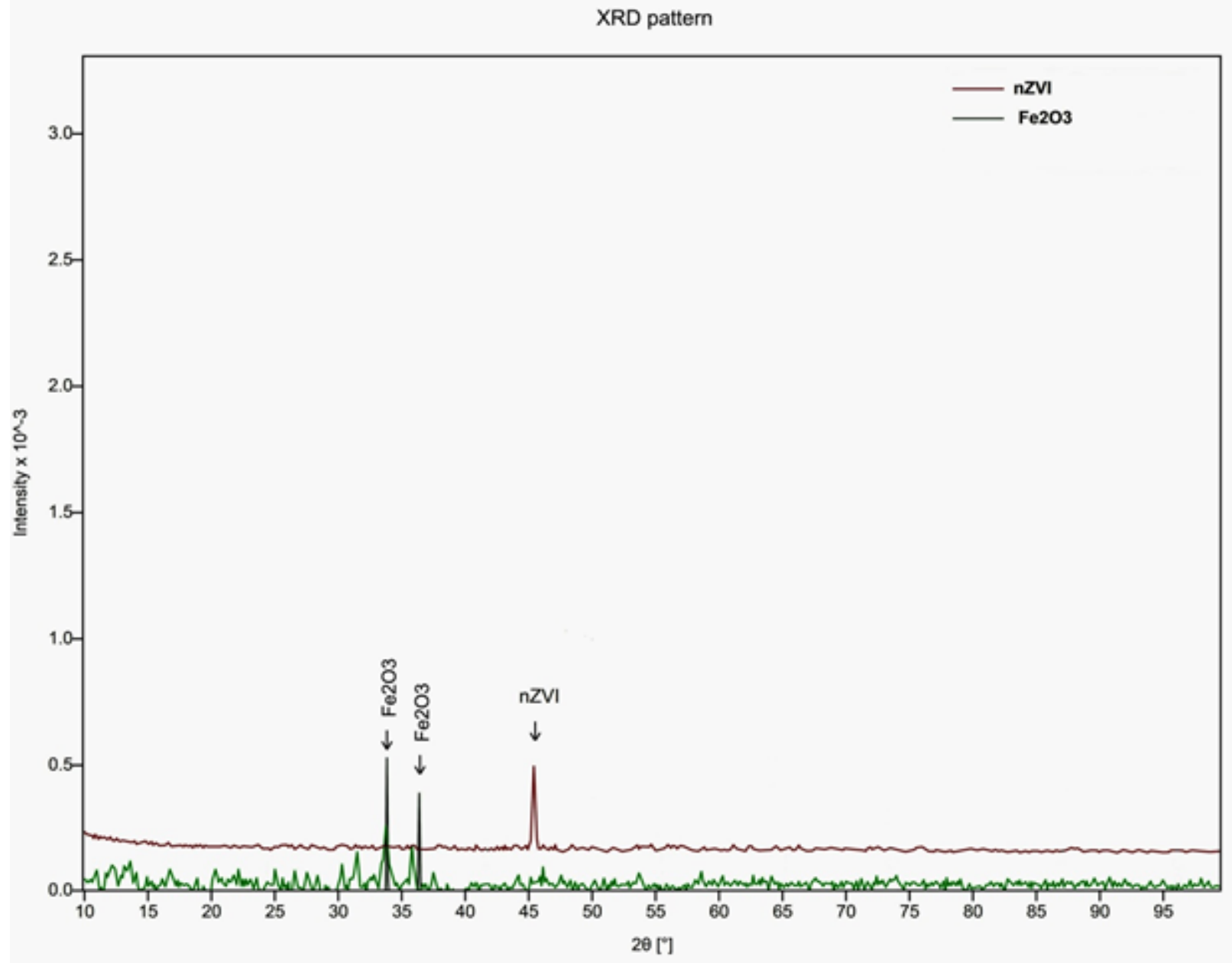

Figure 4

XRD pattern of the green synthesized nanoparticles ( $\mathrm{nZVI}$ ) before reaction and Fe2O3 after reaction 

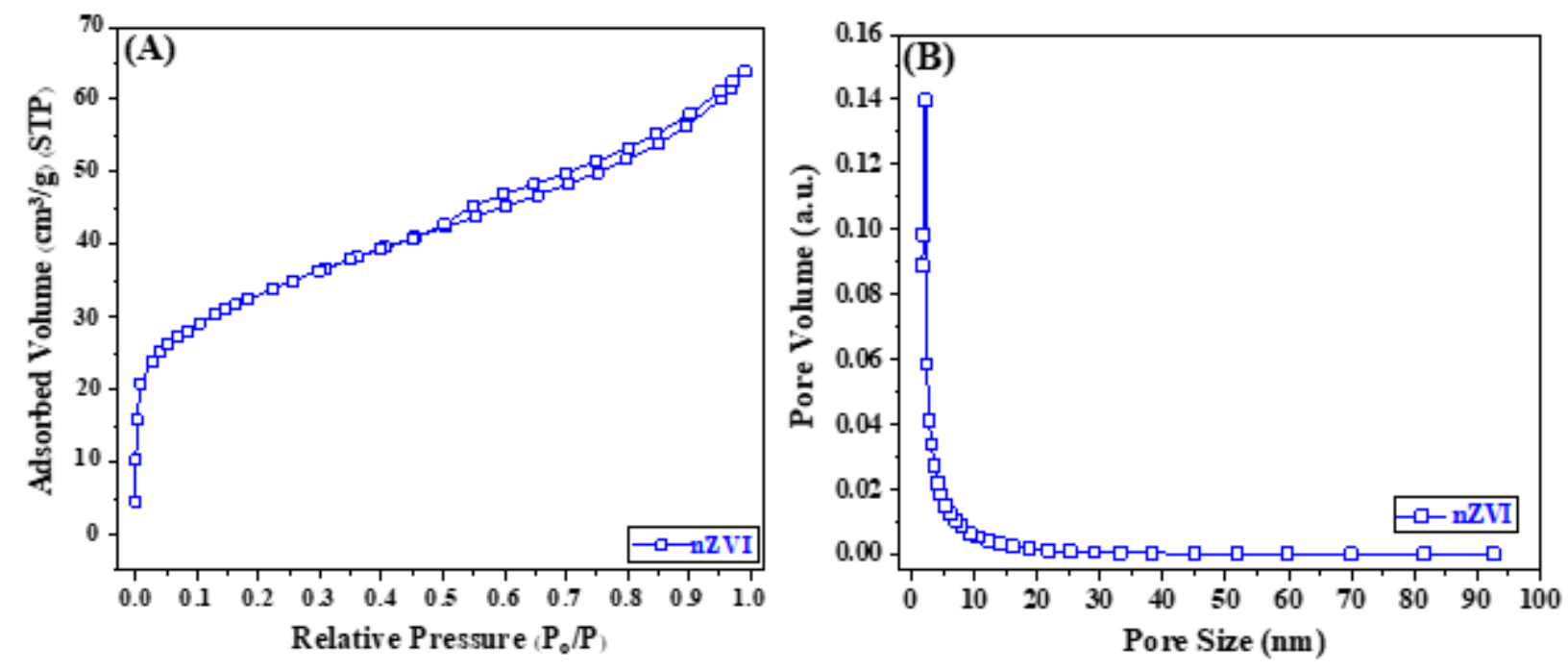

Figure 5

(A) Nitrogen adsorption isotherms of $\mathrm{nZVI}(\mathrm{B})$ and the pore size distribution

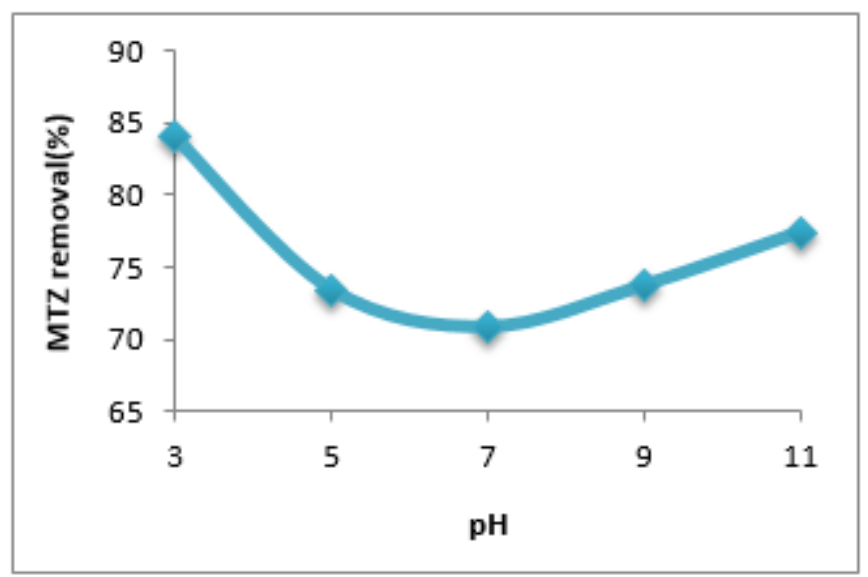

Figure 6

Effect of the $\mathrm{pH}$ on the removal of MTZ (CO $=25 \mathrm{mg} / \mathrm{L}, \mathrm{nZVI}=0.5 \mathrm{~g} / \mathrm{L}, \mathrm{PS}=1.85 \mathrm{~m} \mathrm{M}, \mathrm{T}=30 \mathrm{~min})$

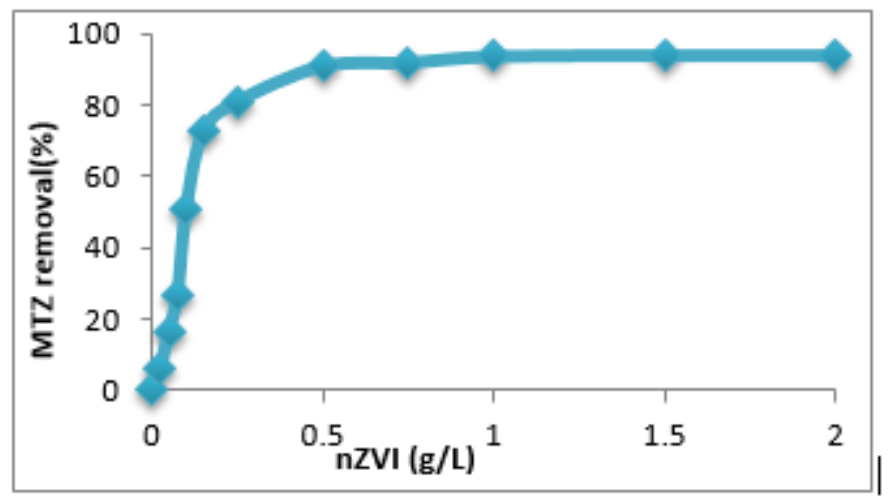

Figure 7 
Effects of $n Z V I$ concentration on the removal of $M T Z(C O=25 \mathrm{mg} / \mathrm{L}, \mathrm{pH}=3, \mathrm{PS}=1.85 \mathrm{~m} \mathrm{M}, \mathrm{T}=30 \mathrm{~min})$

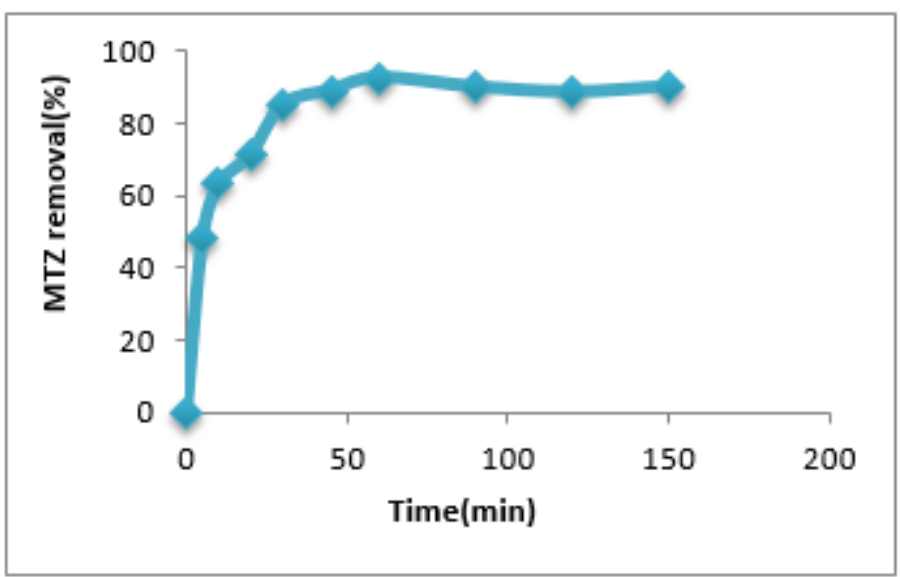

Figure 8

Effects of contact time on the removal of MTZ $(\mathrm{CO}=25 \mathrm{mg} / \mathrm{L}, \mathrm{pH}=3, \mathrm{PS}=1.85 \mathrm{~m} \mathrm{M}, \mathrm{nZVI}=0.5 \mathrm{~g} / \mathrm{L})$

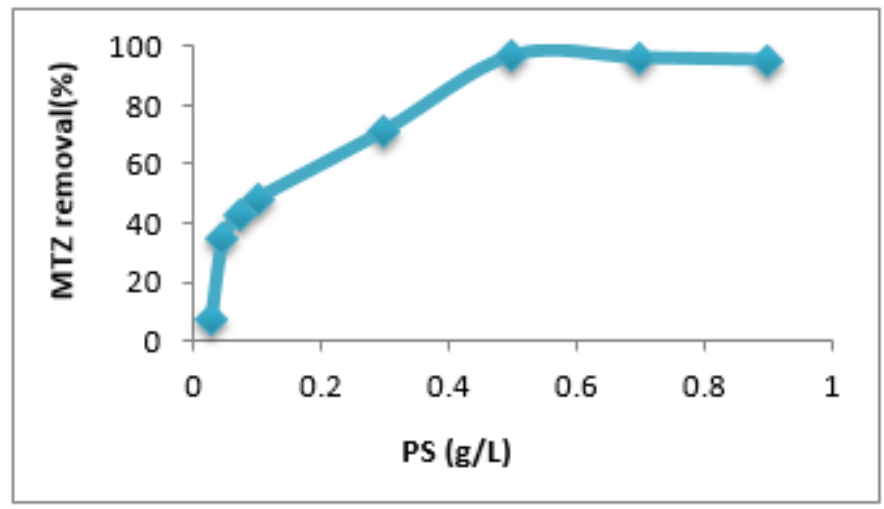

\section{Figure 9}

Effects of PS concentration on the removal of $\mathrm{MTZ}(\mathrm{CO}=25 \mathrm{mg} / \mathrm{L}, \mathrm{pH}=3, \mathrm{~T}=30 \mathrm{~min}, \mathrm{nZVI}=0.5 \mathrm{~g} / \mathrm{L})$

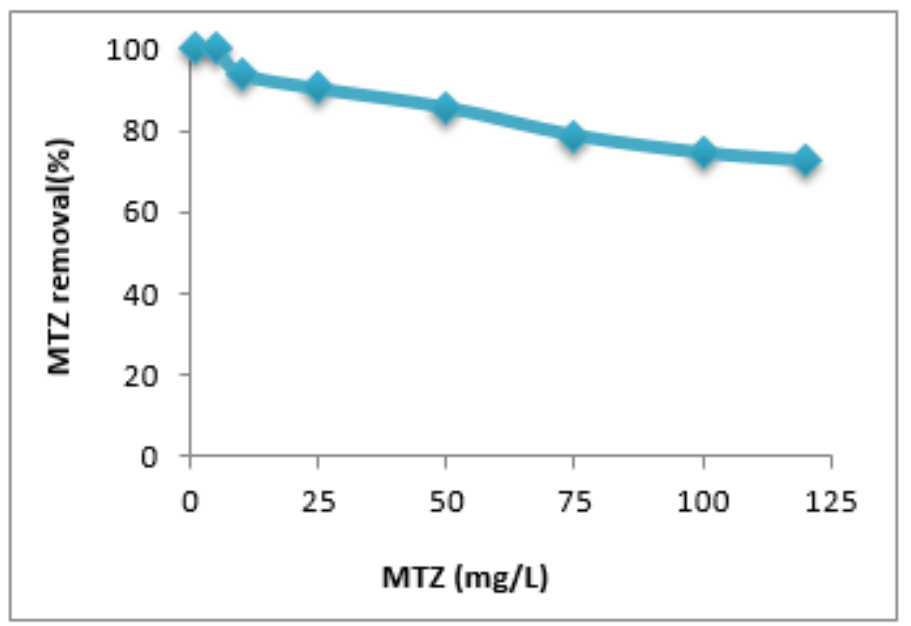

Figure 10 
Effect of initial concentration of MTZ on the process $(P S=1.85 \mathrm{mM}, \mathrm{pH}=3, T=30 \mathrm{~min}, \mathrm{nZVI}=0.5 \mathrm{~g} / \mathrm{L})$

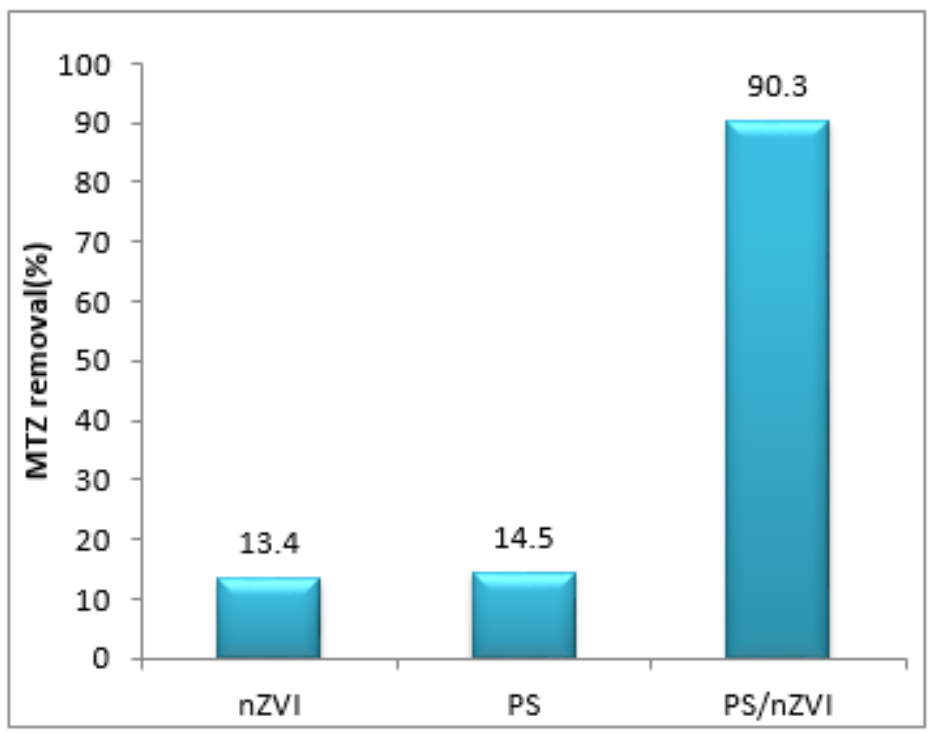

\section{Figure 11}

Synergistic Effect of the PS and nZVI (CO $=25 \mathrm{mg} / \mathrm{L}, \mathrm{PS}=1.85 \mathrm{mM}, \mathrm{pH}=3, \mathrm{~T}=30 \mathrm{~min}, \mathrm{nZVI}=0.5 \mathrm{~g} / \mathrm{L})$

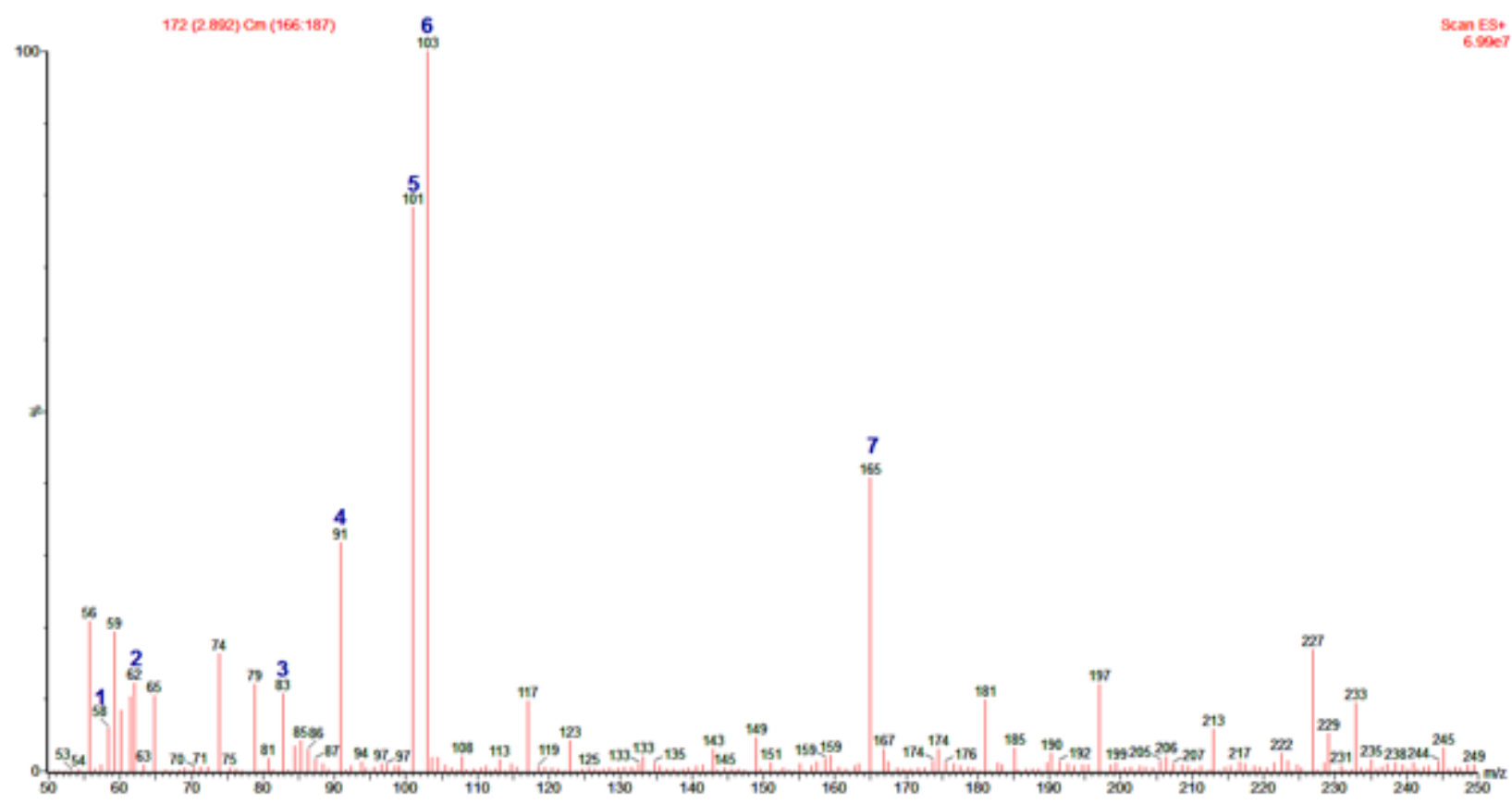

\section{Figure 12}

MTZ oxidation intermediates under optimal condition $(25 \mathrm{mg} / \mathrm{L} \mathrm{MTZ}, \mathrm{pH}=3,0.5 \mathrm{~g} / \mathrm{L} \mathrm{nZVI}, 1.85 \mathrm{mM}$ PS, 30 min contact time).

\section{Supplementary Files}

This is a list of supplementary files associated with this preprint. Click to download. 
- Table1.docx

Page 20/20 